\title{
Awareness of Dementia National Responsibility of Elders: Oral Health Items
}

\author{
Yong-Keum Choi ${ }^{1}$ and Eun-Jeong $\mathrm{Kim}^{2, \dagger}$ \\ ${ }^{1}$ Department of Dental Hygiene, College of Health Science and Genome-based BiolT Convergence Institute, Sun Moon \\ University, Asan 31460, \\ ${ }^{2}$ Department of Preventive and Social Dentistry, School of Dentistry, Seoul National University, Seoul 03080, Korea
}

\begin{abstract}
Background: Dementia is a condition in which a person who has been living a normal life suffers from various cognitive impairments in memory, words, and judgment that considerably disrupt daily life. The oral care ability and subjective oral status of elderly individuals with dementia are lower than those of a healthy person. The oral health care of individuals admitted to nursing homes inevitably falls to nursing assistants and nursing care staff. This study aimed to investigate the need for oral health management items of and to provide basic direction for the future of the Dementia National Responsibility System.

Methods: Elders aged 65 years and over were selected from a comprehensive welfare center. A total of 155 questionnaires were analyzed. The questionnaire consisted of 15 items about general status, 9 items about recognition of the Dementia National Responsibility System, 5 items of the subjective recognition of oral health, and 6 items of the correlation between oral health and dementia.

Results: Among our subjects, 71.0\% answered that they did not know about the Dementia National Responsibility System, 78.7\% answered that they think they need the system, and $81.9 \%$ think that they should add dental health items to the Dementia National Responsibility System. The response to the need for dementia national responsibility, oral health items in the Dementia National Responsibility System, and oral specialists all showed scores of $>4$ points. The need for the Dementia National Responsibility System, oral health items, and specialists were found. Conclusion: It is necessary to include oral health care items in the Dementia National Responsibility System so that elderly individuals with dementia can receive the needed oral health care.
\end{abstract}

Key Words: Aged, Dementia, Dental care

\section{Introduction}

Dementia is a condition in which a person who has been living a normal life suffers from various cognitive deficits in memory, words, and judgment that considerably disrupt daily life ${ }^{1)}$. The prevalence of dementia in elderly people over 65 years of age is approximately $5 \sim 10 \%$, and the number of patients with dementia is expected to double every 20 years until 2050. It is estimated that 840,000 people will be born in 2020, 1.27 million in 2030, and 2.71 million in $2040^{2}$. Dementia is one of the most difficult diseases to manage and currently has no cure. The stress on family caregivers of individuals with dementia now exceeds that of cancer patients. Family conflict, dismissal, and burdens are becoming increasingly more intense ${ }^{3)}$. Although the cause of dementia has not yet been elucidated $^{4}$, experimental studies have suggested that tooth loss and limited masticatory capacity are related to learning and memory capacity ${ }^{5)}$. Dementia is more common in patients with a poor oral health status than in those without cognitive impairment, and affected individuals have fewer remaining teeth than healthy people ${ }^{6}$. In addition, a correlation between oral health and dementia has been reported, as the poor oral environment affects cerebral blood flow due to bacterial aspiration in the oral cavity, while a reduced chewing ability due to tooth loss 
affects brain activation ${ }^{7)}$. In addition, patients with dementia are more likely to have oral disease than healthy individuals; thus, the importance of oral care for elderly individuals with dementia is emphasized ${ }^{7}$. However, the oral care ability and subjective oral status of elderly individuals with dementia is lower than that of healthy people $^{3)}$. Thus, the oral health care of individuals admitted to nursing homes inevitably falls to nursing assistants and nursing care staff.

In Korea, the Dementia National Responsibility System is a policy that was intended to solve the problem of dementia at the national care level rather than the individual family level. The government implemented the Dementia National Responsibility System by reflecting 200 billion won in the budget for dementia ${ }^{8}$. However, the Dementia National Responsibility System includes expansion of the dementia support center, the establishment of a dementia clinic, the introduction of a long-term care insurance system for elderly individuals, 90\% health insurance for dementia, improvements in nursing care, and introduction of the system. The economic contents of the dementia management policy are insufficient. However, the Dementia National Responsibility System has expanded the dementia support center, established a hospital for dementia relief, introduced a ceiling system for long-term care insurance for the elderly, applied 90\% health insurance for dementia, and improved treatment of nursing care workers. Nonetheless, the introduction of a system that addresses only the economic content of the detailed dementia management policy is insufficient $^{8)}$. In particular, there is no information about oral health management items.

Starting in 2015, the Japanese government aimed to promote the understanding and development of dementia. The goal was to educate 8 million dementia supporters by the end of 2017 by spreading the right awareness of dementia and coping with dementia as a society ${ }^{9)}$. This policy is not limited to the location of medical treatment, as it is possible for a dentist to visit a patient at home or in an elderly nursing facility. In addition, staff at Tama Clinic test, diagnose, and rehabilitate disabled and elderly patients with dysphagia due to tooth loss including those with dementia and loss of muscle function around the mouth $^{10)}$. This shows that Korea has a lack of oral care items related to dementia in its national policy compared to Japan.

The purpose of this study was to investigate the need for oral health management items of the Dementia National Responsibility System for elderly people aged 65 years and over and provide a basic direction for future iterations of the Dementia National Responsibility System.

\section{Materials and Methods}

\section{Study participants}

This study was approved by the Institutional Review Board (No. SM-201803-013-1) of the Clinical Research Ethics Review Board of Sun Moon University. Elderly individuals aged 65 years and over were selected from the comprehensive welfare center of the elderly in Asan, Suwon, and Seoul city, between March 23 and April 16, 2018. To calculate the sample size using $G^{*}$ power 3.14 program, the survey required at least 150 people, assuming significance level, effect size, and statistical power of $0.05,0.10$, and 0.95 , respectively. The questionnaires were sent directly to the organizations. The study's purpose was explained verbally, and each participant provided written informed consent. The questionnaires were administered to 165 participants; 10 questionnaires that were not fully completed were excluded, so a total of 155 questionnaires were analyzed.

\section{Study design}

The questionnaire used in this study was based on that used by Lee et al. ${ }^{11)}$. It consisted of 15 items about general status, 9 about awareness of the dementia responsibility system, 5 about subjective recognition of oral health, and 6 about the correlation between oral health and dementia. A 5-point Likert scale was used to assess subjective perception. The self-test consisted of 17 items $^{12)}: 11$ items were 1 and 0 , while 6 items were 2 and 0 . Dementia was classified into three stages: no memory problem, total score of $<3$; pre-dementia, $>4$ points to $<11$ points; and dementia entry, $>12$ points. 


\section{Statistical analysis}

The participants' general characteristics and awareness of the Dementia National Responsibility System were analyzed by frequency analysis. The parametric method was used to analyze normally distributed data, while the non-parametric test was used to analyze non-normally distributed data. The awareness of Dementia National Responsibility System and recognizing the correlation between dementia and oral health according to the dementia self-test group were analyzed by chi-square analysis. A table with $<25 \%$ of the total number of cells with an expected frequency of $<5$ was analyzed by Fisher's extract test. The association between systemic disease, dementia, and oral health according to the dementia self-test group was analyzed by Kruskal-Wallis analysis. The need for dental items in the Dementia National Responsibility System according to the dementia self-test group were also analyzed by the Kruskal-Wallis test. The data collected in this study were analyzed using IBM SPSS version 21.0 software (IBM Corp., Armonk, NY, USA) with a significance level of $\mathrm{p}<0.05$.

\section{Results}

Table 1 shows the patients' general characteristics. The study subjects included 74 men (47.7\%) and 81 women (52.3\%). Of our subjects, $15.5 \%$ were aged $65 \sim 69$ years, $26.5 \%$ were $70 \sim 74$ years, $34.2 \%$ were $75 \sim 79$ years, and $23.9 \%$ were 80 years or older. Among the participants, $40.6 \%$ were living alone, $36.1 \%$ were living with a partner, and $23.2 \%$ were living with their son or daughter. The participants' education levels were as follows: uneducated, 11.6\%; elementary school, 27.7\%; middle school, 23.2\%; high school, 31.0\%; and university, $6.5 \%$. They had the following systemic diseases: diabetes, $6.5 \%$; high blood pressure, 18.1\%; diabetes and high blood pressure, 14.2\%; and others (e.g., heart disease, hyperlipidemia), $10.3 \%$. The most common physical activity was walking (60.6\%) (Table 1).

Most (71.0\%) participants said that they did not know about the Dementia National Responsibility System. Of those who knew of the system, most learned of it through TV (15.5\%). In our cohort, $78.7 \%$ answered that they
Table 1. General Characteristics of Participants $(n=155)$

\begin{tabular}{|c|c|}
\hline Variable & Value \\
\hline \multicolumn{2}{|l|}{ Gender } \\
\hline Men & $74(47.7)$ \\
\hline Women & $81(52.3)$ \\
\hline \multicolumn{2}{|l|}{ Age $(y)$} \\
\hline $65 \sim 69$ & $24(15.5)$ \\
\hline $70 \sim 74$ & $41(26.5)$ \\
\hline $75 \sim 79$ & $53(34.2)$ \\
\hline 80 over & $37(23.9)$ \\
\hline \multicolumn{2}{|l|}{ Living status } \\
\hline Alone & $63(40.6)$ \\
\hline With partner & $56(36.1)$ \\
\hline With son or daughter & $36(23.2)$ \\
\hline \multicolumn{2}{|l|}{ Monthly income (KRW) } \\
\hline Less than 100,0000 & $112(72.3)$ \\
\hline $100,0000 \sim 200,0000$ & $33(21.3)$ \\
\hline More than 200,000 & $10(6.5)$ \\
\hline \multicolumn{2}{|l|}{ Education level } \\
\hline Uneducated & $18(11.6)$ \\
\hline Elementary school & $43(27.7)$ \\
\hline Middle school & $36(23.2)$ \\
\hline High school & $48(31.0)$ \\
\hline University & $10(6.5)$ \\
\hline \multicolumn{2}{|l|}{ Work activity status } \\
\hline Yes & $40(25.8)$ \\
\hline No & $115(74.2)$ \\
\hline \multicolumn{2}{|l|}{ Dementia status } \\
\hline Normal & $67(43.2)$ \\
\hline Pre-dementia & $75(48.4)$ \\
\hline Dementia entry stage & $13(8.4)$ \\
\hline \multicolumn{2}{|l|}{ Chronic disease } \\
\hline Yes & $76(49.0)$ \\
\hline No & $79(51.0)$ \\
\hline \multicolumn{2}{|l|}{ Type of systemic disease } \\
\hline None & $79(51.0)$ \\
\hline Diabate & $10(6.5)$ \\
\hline High blood pressure & $28(18.1)$ \\
\hline Diabate+high blood pressure & $22(14.2)$ \\
\hline Etc. & $16(10.3)$ \\
\hline \multicolumn{2}{|l|}{ Availability } \\
\hline Very possible & $51(32.9)$ \\
\hline Possible & $57(36.8)$ \\
\hline Normal & $40(25.8)$ \\
\hline Impossible & $7(4.5)$ \\
\hline \multicolumn{2}{|l|}{ Physical activities } \\
\hline None & $21(13.5)$ \\
\hline Walking & $94(60.6)$ \\
\hline Stretching & $20(12.9)$ \\
\hline Swimming & $8(5.2)$ \\
\hline Etc. & $12(7.7)$ \\
\hline
\end{tabular}

Data were analyzed by frequency analysis.

Values are presented as $\mathrm{n}(\%)$.

KRW: Korean won. 
needed the Dementia National Responsibility System, while $81.9 \%$ believed that dental health items should be added to the system. The question "What items do you want from the Dementia National Responsibility System?" was answered as follows: expansion of dental fees, $56.8 \%$; mandatory oral health education for caregivers, $10.3 \%$; setup oral management guidance classroom, $18.1 \%$; and expanded oral care visits, $11.6 \%$. A total of $58.1 \%$ answered that they wanted to receive education and treatment, $38.1 \%$ answered they would like to receive tooth maintenance/repair, and $82.6 \%$ responded that oral specialists are needed in the Dementia National Responsibility System (Table 2).

Table 3 shows the results of the chi-square analysis of the dementia self-test group. Most participants who knew about the Dementia National Responsibility System were in the stage of entering the dementia group (53.8\%). In all three groups, elders who knew the Dementia National Responsibility System were informed of the same through TV: no memory problem group, $13.4 \%$; pre-dementia group, $13.3 \%$; and dementia entry group, $38.5 \%$. The three groups answered that they needed the Dementia National Responsibility System ( $\mathrm{p}<0.05)$; likewise, they answered that they needed dental health items from the Dementia National Responsibility System. In addition, they stated that an expansion of dental fees was required in the system. All groups responded that they would like to receive both education and treatment as well as tooth maintenance and repair including medication and treatment. They also stated that oral specialists were needed in the Dementia National Responsibility System. However, no significant difference was noted among the groups.

The association between oral health and systemic disease was noted in all groups, and the proportion of participants who answered that oral health, particularly periodontitis, was related to dementia was high. To the question "Which oral care do you want?", the normal and pre-dementia groups answered expansion of dental medical services for dementia patients, while the dementia entry stage group answered that they wanted customized oral care programs (Table 4).

The association between systemic disease and oral health according to dementia stage group by KruskalWallis analysis showed that the mean score in all groups was 3.37 of 5 points. In addition, the dementia and oral health association was the highest at 3.38 in the dementia entry stage group, 2.84 in the no memory problem group, and 2.87 in the pre-dementia group. There were no significant differences among groups, but there was a similar response in all groups as a result of the association

Table 2. Awareness and Necessity of Dementia National Responsibility System Oral Health Items by Participants $(n=155)$

\begin{tabular}{lc}
\hline \multicolumn{1}{c}{ Variable } & Value \\
\hline Awareness of dementia national responsibility & \\
Know & $45(29.0)$ \\
Do not know & $110(71.0)$ \\
What kind of media did you got information from & \\
Do not know & $109(70.3)$ \\
TV & $24(15.5)$ \\
Newspaper & $8(5.2)$ \\
Internet & $6(3.9)$ \\
Etc. & $8(5.2)$ \\
Necessity of dementia national responsibility & \\
No need & $10(6.5)$ \\
Normal & $23(14.8)$ \\
Need & $122(78.7)$ \\
Necessity of dental health items in dementia national responsibility \\
No need & $10(6.5)$ \\
Normal & $18(11.6)$ \\
Need & $127(81.9)$ \\
What items do you want from dementia national responsibility? \\
Expansion of dental fee & $88(56.8)$ \\
Mandatory oral health education to caregiver & $16(10.3)$ \\
Setup oral management guidance classroom & $28(18.1)$ \\
Expansion of visit oral care & $18(11.6)$ \\
Etc. & $5(3.2)$ \\
What kind of oral care do you want to receive? & \\
Education & $9(5.8)$ \\
Treatment & $51(32.9)$ \\
Education and treatment & $128(82.6)$ \\
Etc. & $90(58.1)$ \\
What kind of medication and treatment do you want to receive? \\
Oral hygiene management education & $23(14.8)$ \\
Tooth maintenance/repair & $59(38.1)$ \\
Periodontal disease treatment & $34(21.9)$ \\
Denture education & $31(20.0)$ \\
Etc. & $8(5.2)$ \\
Necessity of oral specialists in dementia national responsibility \\
No need & $5(3.2)$ \\
Normal & \\
Need & \\
\hline & \\
\hline
\end{tabular}

Data were analyzed by frequency analysis.

Values are presented as $\mathrm{n}(\%)$. 
Table 3. Awareness and Necessity of Dementia National Responsibility System Oral Health Items by Participants according to Dementia Self-Test Group $(n=155)$

\begin{tabular}{|c|c|c|c|c|}
\hline \multirow{2}{*}{ Variable } & \multicolumn{3}{|c|}{ Dementia stage } & \multirow{2}{*}{$\mathrm{p}$} \\
\hline & No memory problem $(n=67)$ & Pre-dementia $(n=75)$ & Dementia entry $(n=13)$ & \\
\hline \multicolumn{4}{|l|}{ Awareness of dementia national responsibility } & 0.146 \\
\hline Know & $18(26.9)$ & $20(26.7)$ & $7(53.8)$ & \\
\hline Do not know & $49(73.1)$ & $55(73.3)$ & $6(46.2)$ & \\
\hline \multicolumn{4}{|l|}{ What kind of media did you got information from } & 0.301 \\
\hline Do not know & $48(71.6)$ & $55(73.3)$ & $6(46.2)$ & \\
\hline TV & $9(13.4)$ & $10(13.3)$ & $5(38.5)$ & \\
\hline Newspaper & $3(4.5)$ & $4(5.3)$ & $1(7.7)$ & \\
\hline Internet & $4(6.0)$ & $1(1.3)$ & $1(7.7)$ & \\
\hline Etc. & $3(4.5)$ & $5(6.7)$ & $0(0)$ & \\
\hline \multicolumn{4}{|l|}{ Necessity of dementia national responsibility } & 0.036 \\
\hline No need & $2(3.0)$ & $8(10.7)$ & $0(0)$ & \\
\hline Normal & $13(19.4)$ & $8(10.7)$ & $2(15.4)$ & \\
\hline Need & $52(77.6)$ & $59(78.7)$ & $11(84.6)$ & \\
\hline \multicolumn{4}{|c|}{ Necessity of dental health items in dementia national responsibility } & 0.267 \\
\hline No need & $4(6.0)$ & $6(80)$ & $0(0)$ & \\
\hline Normal & $9(13.4)$ & $7(9.3)$ & $2(15.4)$ & \\
\hline Need & $54(80.6)$ & $62(82.7)$ & $11(84.6)$ & \\
\hline \multicolumn{4}{|c|}{ What items do you want from dementia national responsibility? } & 0.216 \\
\hline Expansion of dental fee & $31(46.3)$ & $46(61.3)$ & $11(84.6)$ & \\
\hline Mandatory oral health education to caregiver & $9(13.4)$ & $6(8.0)$ & $1(7.7)$ & \\
\hline Setup oral management guidance classroom & $15(22.4)$ & $12(16.0)$ & $1(7.7)$ & \\
\hline Expansion of visit oral care & $10(14.9)$ & $8(10.7)$ & $0(0)$ & \\
\hline Etc. & $2(3.0)$ & $3(4.0)$ & $0(0)$ & \\
\hline \multicolumn{4}{|l|}{ What kind of oral care do you want to receive? } & 0.502 \\
\hline Education & $5(7.5)$ & $4(5.3)$ & $0(0)$ & \\
\hline Treatment & $18(26.9)$ & $29(38.7)$ & $4(30.8)$ & \\
\hline Education and treatment & $42(62.7)$ & $39(52.0)$ & $9(69.2)$ & \\
\hline Etc. & $2(3.0)$ & $3(4.0)$ & $0(0)$ & \\
\hline \multicolumn{4}{|c|}{ What kind of medication and treatment do you want to receive? } & 0.725 \\
\hline Oral hygiene management education & $11(16.4)$ & $9(12.0)$ & $3(23.1)$ & \\
\hline Tooth maintenance/repair & $28(41.8)$ & $25(33.3)$ & $6(46.2)$ & \\
\hline Periodontal disease treatment & $14(20.9)$ & $18(24.0)$ & $2(15.4)$ & \\
\hline Denture education & $11(16.4)$ & $18(24.0)$ & $2(15.4)$ & \\
\hline Etc. & $3(4.5)$ & $5(6.7)$ & $0(0)$ & \\
\hline \multicolumn{4}{|c|}{ Necessity of oral specialists in dementia national responsibility } & 0.313 \\
\hline No need & $3(4.5)$ & $2(2.6)$ & $0(0)$ & \\
\hline Normal & $13(19.4)$ & $9(12.0)$ & $0(0)$ & \\
\hline Need & $51(76.1)$ & $64(85.3)$ & $13(100)$ & \\
\hline
\end{tabular}

Data were analyzed by Fisher's extract test after chi-square analysis.

Values are presented as $\mathrm{n}(\%)$.

between systemic disease, dementia, and oral health (Table 5).

Most responses to the need for the Dementia National Responsibility System, need for oral health items in the system, and need for oral specialists were $>4$ points. The response to the need for the system, need for oral health items in the system, and need for oral specialists all showed scores of $>4$ points. This indicates that elders are aware of the need for the Dementia National Responsibility System, oral health items, and specialists (Table 6).

\section{Discussion}

The Dementia National Responsibility System has 
Table 4. Recognizing the Correlation between Dementia and Oral Health according to Dementia Self-Test Group ( $n=155)$

\begin{tabular}{|c|c|c|c|c|}
\hline \multirow[b]{2}{*}{ Variable } & \multicolumn{3}{|c|}{ Dementia stage } & \multirow[b]{2}{*}{$\mathrm{p}$} \\
\hline & $\begin{array}{l}\text { No memory } \\
\text { problem } \\
(\mathrm{n}=67)\end{array}$ & $\begin{array}{l}\text { Pre-dementia } \\
\quad(n=75)\end{array}$ & $\begin{array}{l}\text { Dementia entry } \\
\qquad(\mathrm{n}=13)\end{array}$ & \\
\hline Association between systemic disease and oral health & & & & 0.263 \\
\hline No & $15(22.4)$ & $21(28.0)$ & $4(30.8)$ & \\
\hline Yes & $52(77.6)$ & $54(72.0)$ & $9(69.2)$ & \\
\hline Association between dementia and oral health & & & & 0.593 \\
\hline No & $24(35.8)$ & $30(40.0)$ & $4(30.8)$ & \\
\hline Yes & $43(64.2)$ & $45(60.0)$ & $9(69.2)$ & \\
\hline Dental diseases related to dementia & & & & 0.337 \\
\hline Dental caries & $14(20.9)$ & $14(18.7)$ & $1(7.7)$ & \\
\hline Periodontal disease & $21(31.3)$ & $34(45.3)$ & $4(30.8)$ & \\
\hline Do not know & $29(43.3)$ & $25(33.3)$ & $8(61.5)$ & \\
\hline Etc. & $3(4.5)$ & $2(2.7)$ & $0(0)$ & \\
\hline Oral care desired from the dementia national responsibility system & & & & 0.022 \\
\hline $\begin{array}{l}\text { Establishment of dental medical supply system for } \\
\text { dementia patients }\end{array}$ & $16(23.9)$ & $4(5.3)$ & $1(7.7)$ & \\
\hline Customized oral care program for dementia patients & $13(19.4)$ & $19(25.3)$ & $6(46.2)$ & \\
\hline $\begin{array}{l}\text { Development and education promotion of oral health medical data } \\
\text { related to dementia }\end{array}$ & $9(13.4)$ & $7(9.3)$ & $1(7.7)$ & \\
\hline Expansion of dental medical services for dementia patients & $21(31.3)$ & $38(50.7)$ & $3(23.1)$ & \\
\hline Support for oral care products for severely demented patients & $8(11.9)$ & $7(9.3)$ & $2(15.4)$ & \\
\hline
\end{tabular}

Data were analyzed by Fisher's extract test after chi-square analysis.

Values are presented as $\mathrm{n}(\%)$.

Table 5. Association between Systemic Disease, Dementia and Oral Health according to Dementia Stage Group

\begin{tabular}{lcccc}
\hline \multirow{2}{*}{ Variable } & \multicolumn{3}{c}{ Dementia stage } & \\
\cline { 2 - 4 } & No memory problem & Pre-dementia & Dementia entry & \\
\hline Association between systemic disease and oral health & $3.51 \pm 2.61$ & $3.28 \pm 1.17$ & $3.31 \pm 1.32$ & 0.886 \\
Association between dementia and oral health & $2.84 \pm 1.15$ & $2.87 \pm 1.18$ & $3.38 \pm 1.33$ & 0.735 \\
\hline
\end{tabular}

Data were analyzed by Kruskal-Wallis analysis.

A 5-point Likert scale was used to assess subjective perception; no need at all=1, no need=2, normal=3, need=4, very need=5.

Values are presented as mean \pm standard deviation.

Table 6. Necessity of Oral Health Items and Specialists in Dementia National Responsibility according to Dementia Stage Group

\begin{tabular}{lcccc}
\hline \multicolumn{1}{c}{ Variable } & \multicolumn{3}{c}{ Dementia stage } \\
\cline { 2 - 4 } & No memory problem & Pre-dementia & Dementia entry & \\
\hline Necessity of dementia national responsibility & $4.06 \pm 0.9$ & $3.97 \pm 1.04$ & $4.54 \pm 0.78$ & 0.107 \\
Necessity of dental health items in dementia national responsibility & $4.11 \pm 0.86$ & $4.02 \pm 0.93$ & $4.46 \pm 0.78$ & 0.22 \\
Necessity of oral specialists in dementia national responsibility & $4.15 \pm 0.94$ & $4.21 \pm 0.81$ & $4.62 \pm 0.51$ & 0.228 \\
\hline
\end{tabular}

Data were analyzed by Kruskal-Wallis analysis.

A 5-point Likert scale was used to assess subjective perception; no need at all=1, no need=2, normal=3, need=4, very need=5.

Values are presented as mean \pm standard deviation.

insufficient information about dementia management policy and no information about dental health management items compared with other countries. Although many studies have reported on the relationship between oral health and dementia, the management ability of patients with dementia is low ${ }^{4)}$, and the oral health care programs 
of elderly individuals who are admitted to nursing homes are administered by the facility manager ${ }^{7)}$. Korea currently has an aging society ${ }^{12)}$, and the numbers of dementia patients are rapidly increasing as a result ${ }^{2}$. This study aimed to investigate the need for oral health management items in the Dementia National Responsibility System for elderly people aged 65 years and over and provide a basic direction for future iterations of the Dementia National Responsibility System in Korea.

According to our participants' general characteristics, our study included more women (52.3\%) than men, patients aged $75 \sim 79$ years $(34.2 \%)$, and patients living alone $(40.6 \%)$. Most household incomes were lower than 1 million won (72.3\%), and most participants were retired (74.2\%). In addition, more elderly individuals were at the pre-dementia level (48.4\%) than without memory problems, and most of the behaviors were possible (95.5\%). We found that most elderly people do not know about the Dementia National Responsibility System (71.0\%), the system is needed $(78.7 \%)$, and the Dementia National Responsibility System requires the addition of oral health items $(81.9 \%)$.

In the results of the survey of the dementia self-test group's perception about the Dementia National Responsibility System, more elderly people in the normal and pre-dementia groups did not now about the system. These results suggest that elderly people who are more likely to benefit from the Dementia National Responsibility System are not well aware of this system, indicating that it requires much publicity. Most of the elders who replied that they knew about the Dementia National Responsibility System learned about it via TV. Various media will be available to raise awareness of the system. All groups stated that oral care treatment and education were needed; among the oral care items, the highest demand was for maintenance/repair of teeth. Educating patients and caregivers about the importance of primary prevention, along with treatment, should be actively provided to increase patient oral health levels by increasing selfconfidence and participation ${ }^{13)}$. This finding suggests that if oral health management items are added to the Dementia National Responsibility System, treatment and education should be combined.
The association between systemic disease and oral health was reported in all groups, while the association between dementia and oral health was more likely to be associated only with the dementia group. No significant difference was seen in terms of systemic disease and dementia and oral health associations on the 5-point Likert scale, but there was a similar response in all groups in terms of the associations between systemic disease, dementia, and oral health. No significant difference was noted in the Dementia National Responsibility System or the need for dental health items and experts by dementia classification; rather, it was high in all groups. In many previous studies, the presence or absence of teeth showed a statistically significant increase in the risk of dementia, indicating that dementia and oral health were correlated ${ }^{14-17)}$. Cognitive dysfunction was associated with tooth loss and a subsequent failure to do well ${ }^{14)}$. Moreover, the number of teeth was associated with calculation ability, while the use of artificial teeth was associated with the preservation of cognitive function in Japanese elders ${ }^{15)}$. However, most of the participants responded that there is no correlation between dementia and oral health. Therefore, there is a need to improve this perception.

This study has some limitations. First, it is difficult to represent the entire country because we used an extracted convenience sample from some regions. Therefore, it would be better to conduct surveys of more public institutions in the future. Second, there is error in assessing the extent to which the understanding of the Dementia National Responsibility System is low and relatively few questionnaire responses were included. Therefore, to obtain more accurate data regarding the system, it is necessary to promote it and increase the public's perception of it. Third, the elderly who answered the questionnaire in this study were classified as having self-diagnosed dementia, but most were healthy. However, since our study subjects were elderly, memory errors were possible. We tried to increase the accuracy of this part using several questionnaires. Finally, the research on this subject is very rare and comparable previous studies are lacking. It is likely that substantial research will be performed in the future.

Despite these limitations, this study suggests that 
dementia is associated with oral health and is a starting point for providing dental health care for elderly people. It is also meaningful that this study can contribute to the establishment of a dental treatment and education system for elderly individuals with dementia and the need for oral health care items. Although awareness of the Dementia National Responsibility System was low, it was confirmed that $>90 \%$ of oral care items were identified as needed, so many people wanted oral as well as systemic care.

In conclusion, it is necessary to establish measures to include oral health management items in the Dementia National Responsibility System so that elderly individuals with dementia can access the necessary oral health care items.

\section{Notes}

\section{Conflict of interest}

No potential conflict of interest relevant to this article was reported.

\section{Ethical approval}

This study was approved by the Institutional Review Board (No. SM-201803-013-1) of the Clinical Research Ethics Review Board of Sun Moon University.

\section{ORCID}

Yong-Keum Choi, https://orcid.org/0000-0002-5537-4208 Eun-Jeong Kim, https://orcid.org/0000-0002-6316-7807

\section{References}

1. Korea Prevention of Dementia Association: Definition of dementia. Retrieved May 10, 2018, from http://www.chimae. or.kr/bbs/board.php?bo_table=chimae_dic\&wr_id=6\& page $=2(2018)$.

2. Korea Prevention of Dementia Association: Prevalence and incidence of dementia. Retrieved May 9, 2018, from http://www. chimae.or.kr/bbs/board.php?bo_table=chimae_dic\&wr_id=4\&pag $\mathrm{e}=2$ (2018).

3. Dementia national responsibility. Retrieved May 9, 2018, from https://hoy.kr/IlSPh(2018).

4. Go HB, Kim MG, Kim JY, et al.: The relationship between dementia and oral health in some elderly in Daejeon. J Dent Hyg Sci 16: 481-487, 2016.

https://doi.org/10.17135/jdhs.2016.16.6.481

5. Listl S: Oral health conditions and cognitive functioning in middle and later adulthood. BMC Oral Health 14: 70, 2014. https://doi.org/10.1186/1472-6831-14-70

6. Elsig F, Schimmel M, Duvernay E, et al.: Tooth loss, chewing efficiency and cognitive impairment in geriatric patients. Gerodontology 32: 149-156, 2015. https://doi.org/10.1111/ger.12079

7. Cho NI, Park SY, Lee HS, Oh HY: Oral health knowledge and behavior among nursing home employees in Seoul, Korea. J Korean Acad Oral Health 37: 16-24, 2013. https://doi.org/10.11149/jkaoh.2013.37.1.16

8. Naver Wikipedia: Dementia national responsibility. Retrieved May 9, 2018, from http://terms.naver.com/entry.nhn?docId= $3596636 \&$ cid $=43667 \&$ categoryId=43667 (2017, June 28).

9. DementiaNews: US-UK-Japan How does the developed country dentist policy differ from Korea? Retrieved May 9, 2018, from https://www.dementianews.co.kr/?p=3827.html (2017, August 29).

10. Jeon MJ, Lee BJ, Kim DK: Oral health status of elderly long-term hospitalized patients with and without dementia in Jeollanam-do, South Korea. J Korean Acad Dent Health 32: 299-308, 2008.

11. Lee TJ, Jung JO, Lee KH: A study on the status of the senior citizens' oral health in some areas. J Korean Soc Dent Hyg 12: 801-815, 2012.

12. Retrieved January 9, 2018, from http://www.mois.go.kr/frt/ bbs/type010/commonSelectBoardArticle.do?bbsId=BBSMS TR_000000000008\&nttId=61421(2018).

13. Lee HO, Kim J: Effects of elders' oral health beliefs and oral health behaviors on their quality of life. J Dent Hyg Sci 8: 57-63, 2008.

14. Delwel S, Binnekade TT, Perez RSGM, et al.: Oral hygiene and oral health in older people with dementia: a comprehensive review with focus on oral soft tissues. Clin Oral Investig 22: 93-108, 2018. https://doi.org/10.1007/s00784-017-2264-2

15. Kato H, Takahashi Y, Iseki C, et al.: Tooth loss-associated cognitive impairment in the elderly: a community-based study in Japan. Intern Med 2019. [Epub ahead of print] https://doi.org/10.2169/internalmedicine.1896-18

16. Chen J, Ren CJ, Wu L, et al.: Tooth loss is associated with increased risk of dementia and with a dose-response 
relationship. Front Aging Neurosci 18: 1-9, 2018.

https://doi.org/10.3389/fnagi.2018.00415

17. Fang WL, Jiang MJ, Gu BB, et al.: Tooth loss as a risk factor for dementia: systematic review and meta-analysis of 21 observational studies. BMC Psychiatry 18: 1-11, 2018.

https://doi.org/10.1186/s12888-018-1927-0 